\title{
Consumo e digestibilidade de dietas contendo níveis de farelo do mesocarpo de babaçu para ovinos ${ }^{1}$
}

\author{
Intake and digestibility of sheep diets containing levels of babassu-mesocarp meal
}

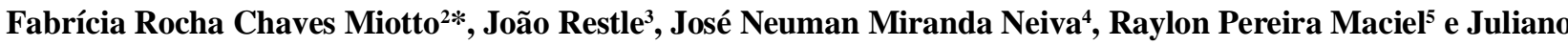 \\ José de Rezende Fernandes ${ }^{6}$
}

\begin{abstract}
RESUMO - Objetivou-se avaliar o consumo, a digestibilidade aparente de nutrientes e o balanço de nitrogênio de dietas contendo farelo de mesocarpo de babaçu (FMB) em substituição à silagem de capim elefante $(0 ; 21 ; 38 ; 62$ e 78\%). Utilizaram-se 20 ovinos alojados em gaiolas metabólicas individuais e distribuídos em delineamento inteiramente casualizado com quatro repetições. Foram coletados e registrados o consumo de alimentos e excreções de fezes e urina. Os consumos de matéria seca, matéria orgânica, proteína bruta, cinzas, fibra em detergente neutro, fibra em detergente ácido, hemicelulose e carboidratos totais não foram influenciados pelas dietas experimentais. Foi observada alteração nos consumos de carboidratos não fibrosos (CCNF) e redução nos consumos de extrato etéreo em \% do PV e em gramas por unidade de tamanho metabólico $\left(\mathrm{g} \mathrm{UTM}^{-1}\right)$. O consumo de nutrientes digestíveis totais (CNDT) teve comportamento quadrático com pontos de máximo em 37,3 e 37,9\% de FMB expressos em \% PV e g UTM ${ }^{-1}$, respectivamente. As digestibilidades aparentes da matéria orgânica, fibra em detergente neutro, fibra em detergente ácido, proteína bruta e carboidratos não fibrosos reduziram na medida em que o FMB aumentou nas dietas. As digestibilidades aparentes da matéria seca (DAMS), extrato etéreo e carboidratos não fibrosos tiveram comportamento quadrático, com máxima DAMS estimada em 10\% de FMB. O NDT reduziu 0,28\% para cada ponto percentual de inclusão de FMB nas dietas. A adição do FMB reduziu a digestibilidade das frações fibrosas e aumentou o CCNF e o CNDT, o que indica que este subproduto pode ser utilizado como fonte energética em dietas para ruminantes.
\end{abstract}

Palavras-chave: Carboidratos não fibrosos. Fibra em detergente neutro. Subproduto. Teor de carboidratos.

\begin{abstract}
The objective of this study was to evaluate the intake, apparent digestibility of nutrients and the nitrogen balance of diets containing babassu-mesocarp meal (BMM) as a replacement for elephant-grass silage (0, 21, 38, 62 and 78\%). Twenty sheep were used, housed in individual metabolic cages and distributed in a completely randomized design with four replications. Food intake was noted and faeces and urine excretions were collected and recorded. Intake of dry matter, organic matter, crude protein, ash, neutral-detergent fibre, acid-detergent fibre, hemicellulose, and total carbohydrate was not affected by the experimental diets. Changes were observed in the non-fibrous carbohydrates intake (INFC) and a reduction in the intake of ether extract as a \% of live weight (LW) and grams per unit of metabolic body size $\left(\mathrm{g} \mathrm{MBS}^{-1}\right)$. Total digestible nutrient intake (ITDN) presented quadratic behaviour, with maximum points at $37.3 \%$ and $37.9 \%$ of BMM expressed as \%LW and $\mathrm{g} \mathrm{MBS}^{-1}$ respectively. The apparent digestibility of organic matter, neutral-detergent fibre, acid-detergent fibre, crude protein and non-fibrous carbohydrate decreased with the increase in BBM in the diet. The apparent digestibility of dry matter (ADDM), ether extract and non-fibrous carbohydrates showed a quadratic response, with maximum ADDM estimated at $10 \%$ of BMM. The TDN decreased by $0.28 \%$ for each percentage point of BMM added to the diet. The addition of BMM reduced digestibility of the fibres and increased both INFC and ITDN, indicating that this byproduct can be used as an energy source in ruminant diets.
\end{abstract}

Key words: Non-fibrous carbohydrates. Neutral-detergent fibre. By-products. Carbohydrates content.

\footnotetext{
*Autor para correspondência

${ }^{1}$ Recebido para publicação em 12/03/2011; aprovado em 01/05/2012

Parte da Tese do primeiro autor; Pesquisa financiada pelo CNPq

${ }^{2}$ Curso de Zootecnia, Fundação Universidade Federal do Tocantins, Araguaína-TO, fabriciarchaves@ hotmail.com

${ }^{3}$ Curso de Zootecnia, Fundação Universidade Federal do Tocantins, Araguaína-TO, jorestle @ terra.com.br

${ }^{4}$ Curso de Zootecnia, Fundação Universidade Federal do Tocantins, Araguaína-TO, araguaia2007@ gmail.com

${ }^{5}$ Curso de Pós-Graduação em Ciência Animal Tropical, Fundação Universidade Federal do Tocantins, Araguaína-TO, raylonmaciel@yahoo.com.br

${ }^{6}$ Departamento de Produção Animal, Universidade Federal de Goiás, Campus II, Goiânia-GO, juliano@ vet.ufg.br
} 


\section{INTRODUÇÃO}

A região Norte do Brasil, reconhecida pela produção de bovinos a pasto, experimenta nos últimos anos incremento na criação de animais em confinamento, principalmente, devido às limitações para aberturas de novas áreas para formação de pastagens. Entretanto, a oferta de matéria prima para produção de concentrados ainda é um importante limitante para expansão deste sistema de produção. Conforme Pacheco et al. (2006), a alimentação representa um dos principais componentes dos custos de produção, dependendo o êxito da exploração intensiva da disponibilidade e custos dos alimentos a serem aproveitados para a formulação das dietas.

$\mathrm{O}$ uso de alimentos alternativos visando a redução dos custos deve ser buscada sem prejudicar o desempenho animal (NEIVA et al., 2005), considerando que a ingestão de alimentos é influenciada tanto pela estrutura física, como pela composição química das dietas (CARVALHO et al., 2004). Neste sentido, diversas pesquisas têm sido realizadas na busca pelo aproveitamento de resíduos agroindustriais (MIOTTO et al., 2009; MORENO et al., 2010; OLIVEIRA et al., 2010; ZAMBOM et al., 2008), potenciais ingredientes para ração animal, em especial alternativas regionais que apresentem baixo custo e logística favorável.

Entre as espécies de palmeiras utilizadas na indústria extrativista brasileira está o babaçu (Orbygnia sp.), palmeira oleaginosa que possui grande valor industrial e comercial, sendo encontrada em extensas áreas em estados como Maranhão, Piauí e Tocantins. Na industrialização do coco do babaçu para produção de óleo comestível são produzidos vários subprodutos como farelo de mesocarpo do babaçu e farinha de mesocarpo, que correspondem em média a $23 \%$ do peso do fruto. Pavlak et al. (2007) encontraram teor de amido na farinha do mesocarpo de babaçu de aproximadamente $52 \%$, variável conforme fatores genéticos, climáticos e edáficos, existentes na região. Pelo volume de produção e características físico-químicas apresentadas, o farelo do mesocarpo de babaçu tem demonstrado potencial para uso na alimentação de ruminantes, uma vez que já vem sendo utilizado como alimento por produtores da região, contudo, sem qualquer caracterização bromatológica ou real especificação de seu real valor nutricional, visto que raros estudos são encontrados na literatura (GUIMARÃES, 2010; SILVA, 2008).

Objetivou-se avaliar neste estudo o consumo voluntário e a digestibilidade aparente de dietas para ovinos contendo níveis crescentes de farelo do mesocarpo de babaçu utilizado em substituição à silagem de capim elefante.

\section{MATERIAL E MÉTODOS}

O experimento foi realizado na Escola de Medicina Veterinária e Zootecnia (EMVZ) da Universidade Federal do Tocantins (UFT), no município de Araguaína, localizada na região Norte do Tocantins, $07^{\circ} 11^{\prime} 28^{\prime \prime}$ de Latitude Sul, e $48^{\circ} 12^{\prime} 26^{\prime \prime}$ de Longitude Oeste. Foram testados cinco níveis de substituição $(0 ; 21 ; 38 ; 62$ e $78 \%$, com base na matéria seca total) da silagem de capim elefante pelo farelo do mesocarpo de babaçu (Orbygnia sp.), sendo a dieta sem FMB chamada de dieta padrão.

O farelo do mesocarpo de babaçu (FMB) utilizado no presente trabalho foi obtido na empresa Tobasa Bioindustrial de Babaçu S.A., no Estado do Tocantins. Este subproduto é obtido pelo processo de moagem do mesocarpo do babaçu, quando da industrialização deste para extração da amêndoa, apresentando granulometria fina e elevada pulverulência. O capim elefante utilizado foi cortado manualmente, com 60 dias de rebrotação e processado em picadora de forragem convencional regulada para corte de partículas com 1 a $2 \mathrm{~cm}$ de comprimento e armazenado em barris de PVC com capacidade para $200 \mathrm{~L}$. Cada silo recebeu $140 \mathrm{~kg}$ de forragem e a silagem foi compactada por pisoteamento, obtendo-se densidade de $700 \mathrm{kgm}^{-3}$. Para a vedação dos silos foram utilizadas lonas plásticas presas com ligas de borracha. A composição bromatológica do FMB e das dietas experimentais é apresentada na Tabela 1. Em virtude do baixo teor de proteína bruta do FMB (aproximadamente 3,5\%) foi realizado o ajuste desta adicionando-se $2 \%$ de uréia pecuária a este. Este procedimento visava que a substituição da silagem por FMB não reduzisse o teor de proteína bruta da dieta. Como os ingredientes das dietas corresponderam apenas ao FMB e silagem de capim elefante, a composição bromatológica da dieta $0 \%$, sem FMB, corresponde à composição da silagem.

Para o ensaio utilizaram-se 20 ovinos machos, castrados, sem raça definida, com idade média de oito meses, peso vivo médio de $30,82 \mathrm{~kg} \pm 4,17$ e peso metabólico médio de 13,06 kg $\pm 1,34$. Os animais foram devidamente vermifugados e alojados em gaiolas metabólicas individuais, com acesso a bebedouro, comedouro e cocho para fornecimento de sal mineral à vontade. Os animais foram distribuídos em delineamento inteiramente casualizado com cinco tratamentos e quatro repetições. O experimento teve duração de 19 dias, com 14 dias de adaptação e cinco dias para coletas experimentais.

O fornecimento dos alimentos foi realizado diariamente em dois períodos, às 8 e 16 horas, permitindo $10 \%$ de sobras e procedendo-se a coleta de amostras da silagem e do FMB, além de amostras das sobras no horário da manhã. Aurina e as fezes eram coletadas em recipientes 
Tabela 1 - Composição bromatológica das dietas experimentais e do farelo de mesocarpo do babaçu (FMB)

\begin{tabular}{|c|c|c|c|c|c|c|}
\hline \multirow[t]{2}{*}{ Itens } & \multicolumn{5}{|c|}{$\begin{array}{c}\text { Níveis de substituição da silagem por } \\
\text { FMB }(\%) \\
\end{array}$} & \multirow[t]{2}{*}{$\mathrm{FMB} * *$} \\
\hline & $0 *$ & 21 & 38 & 62 & 78 & \\
\hline Matéria seca, $\% \mathrm{MN}^{1}$ & 21,3 & 33,4 & 47,4 & 60,8 & 74,9 & 89,3 \\
\hline Matéria orgânica, \% MS $^{2}$ & 95,9 & 95,9 & 95,9 & 95,9 & 96,0 & 95,4 \\
\hline Proteína bruta, \% MS & 5,4 & 5,8 & 6,2 & 6,6 & 7,1 & 7,5 \\
\hline Fibra em detergente neutro, $\% \mathrm{MS}$ & 78,5 & 72,7 & 66,2 & 59,9 & 53,2 & 46,4 \\
\hline Fibra em detergente ácido, \% MS & 49,3 & 46,5 & 43,3 & 40,3 & 37,1 & 33,8 \\
\hline Hemicelulose, \% MS & 29,2 & 26,2 & 22,8 & 19,6 & 16,1 & 12,5 \\
\hline Lignina, \% MS & 8,1 & 8,8 & 9,8 & 10,6 & 11,6 & 12,5 \\
\hline Nitrogênio insolúvel em detergente neutro (NIDN), \% do $\mathrm{N}$ total & 19,3 & 18,0 & 16,9 & 15,2 & 13,7 & 12,2 \\
\hline Nitrogênio insolúvel em detergente ácido (NIDA), \% do $\mathrm{N}$ total & 11,2 & 11,0 & 10,9 & 10,7 & 10,5 & 10,3 \\
\hline Carboidratos totais, $\% \mathrm{MS}$ & 87,3 & 87,4 & 87,5 & 87,7 & 87,7 & 87,8 \\
\hline Carboidratos não fibrosos, \% MS & 8,8 & 14,6 & 21,3 & 27,7 & 34,5 & 41,4 \\
\hline Extrato etéreo, \% MS & 1,9 & 1,8 & 1,5 & 1,2 & 0,9 & 0,7 \\
\hline Cinza, \% MS & 4,1 & 4,1 & 4,1 & 4,1 & 4,0 & 4,1 \\
\hline
\end{tabular}

${ }^{1} \mathrm{MN}$ - matéria natural; ${ }^{2} \mathrm{MS}$ - matéria seca; ${ }^{*} \mathrm{~A}$ dieta sem FMB $(0 \%)$ é composta apenas por silagem de capim elefante, portanto, a sua composição bromatológica é a composição obtida para a silagem. ** adicionado $2 \%$ de uréia com base na matéria seca

separados (baldes), posicionados sob as gaiolas. Nos recipientes coletores de urina eram adicionados $20 \mathrm{~mL}$ de ácido clorídrico 1:1, para evitar as perdas de nitrogênio por volatilização. Diariamente, foi realizada a coleta total de fezes e urina, as quais foram pesadas e amostradas para posteriores análises laboratoriais. As amostras foram acondicionadas em congelador e conservadas sob congelamento $\left(-5 \mathrm{a}-10{ }^{\circ} \mathrm{C}\right)$.

Ao término do ensaio as amostras de sobras, silagem, FMB e fezes foram descongeladas, formadas amostras compostas para cada repetição e alimento, secas e trituradas em moinho tipo Willey com malha de $1 \mathrm{~mm}$. As análises bromatológicas e de nitrogênio urinário foram realizadas no laboratório de Nutrição Animal da EMVZ/ UFT, Araguaína, seguindo-se as recomendações de Silva e Queiroz (2002) para: matéria seca (MS), cinzas (CZ) para cálculo da matéria orgânica $(\mathrm{MO})$, proteína bruta $(\mathrm{PB})$, extrato etéreo (EE), fibra em detergente neutro (FDN), fibra em detergente ácido (FDA), hemicelulose (HEM), carboidratos não fibrosos (CNF), carboidratos totais (CHOT) e nutrientes digestíveis totais (NDT).

O consumo de nutrientes foi determinado em gramas por dia $\left(\mathrm{g} \mathrm{dia}^{-1}\right), \%$ do peso vivo (\%PV) e grama por unidade de tamanho metabólico (g UTM $\left.{ }^{1}\right)$. A digestibilidade dos nutrientes foi avaliada em percentual e o balanço aparente de nitrogênio $(\mathrm{BN})$ foi expresso em $\mathrm{g} \mathrm{dia}^{-1}$, em que BN $=$ Ningerido $-($ Nfezes +
Nurina); e o Ningerido = Nofertado - Nsobras (SILVA; LEÃO, 1979). Os valores que compõem os CHOT; CNF e NDT foram estimados conforme Sniffen et al. (1992), conforme as equações 1; 2 e 3.

$$
\begin{aligned}
& \mathrm{CHOT}=100-(\% \mathrm{~PB}+\% \mathrm{EE}+\% \mathrm{CZ}) \\
& \mathrm{CNF}=100-(\% \mathrm{~PB}+\% \mathrm{EE}+\mathrm{CZ}+\% \mathrm{FDN}) \\
& \mathrm{NDT}=\mathrm{PBD}+\mathrm{FDND}+\mathrm{CNFD}+(\mathrm{EED} \times 2,25)
\end{aligned}
$$

em que: $\mathrm{PBD}=\mathrm{PB}$ digestível; FDND = FDN digestível; $\mathrm{CNFD}=\mathrm{CNF}$ digestível e EED $=$ EE digestível .

Para avaliação do efeito dos níveis de adição do FMB, foram realizadas análises de variância (teste F), de regressão e de correlação de Pearson. $\mathrm{Na}$ regressão, a escolha do modelo mais adequado para cada variável baseou-se na significância dos coeficientes linear, quadrático e cúbico, utilizando-se o nível de 0,05 de significância. Antes dessas análises, verificaram-se as pressuposições de distribuição normal e homocedasticidade. As características que não atenderam estas pressuposições foram transformadas para se prosseguir as análises estatísticas. Foram transformados os dados de consumo de CNF em $\mathrm{g} \mathrm{dia}^{-1}$ para $1 \mathrm{CCNF}^{-1}$; consumo de $\mathrm{PB}$ em g dia ${ }^{-1}$ para $\log ^{10}(\mathrm{CPB})$; consumo de PB em \% PV para $\log ^{10}(\mathrm{CPB})$; consumo de $\mathrm{PB}$ em g UTM ${ }^{-1}$ para $\log ^{10}(\mathrm{CPB})$; digestibilidade da FDA para DFDA+3 e digestibilidade do EE para (DEE+200) ${ }^{2}$. 


\section{RESULTADOS E DISCUSSÃO}

Os consumos de MS (CMS); MO (CMO) e PB (CPB) em $\mathrm{g} \mathrm{dia}^{-1}, \% \mathrm{PV}$ e $\mathrm{g} \mathrm{UTM}^{-1}$ não foram alterados pela inclusão de FMB às dietas (Tabela 2). A não significância estatística dos dados pode ser efeito dos elevados coeficientes de variação (CV) obtidos, mais elevados que os observados na literatura para este tipo de observação, ficando em torno de $20 \%$ (BOLZAN et al. 2007; RÊGO et al., 2010). Os CV elevados podem ser decorrentes da variação comportamental dos animais, relacionada à aceitação individual das dietas experimentais corroborado com o número reduzido de ovinos por tratamento e de dias de observação, mesmo atendendo-se o período recomendado de adaptação.
Segundo Forbes (1999), a aceitabilidade antes pensada como uma característica do alimento, agora é vista individualmente como função do animal, nascendo estes com preferências e aversões inatas por determinados alimentos. Desta forma, animais de uma mesma espécie, mesmo contemporâneos, podem comportar-se de forma diferente quando recebem uma mesma dieta. Durante o período experimental foi observado que animais de pesos semelhantes e recebendo a mesma dieta experimental, apresentaram comportamentos diferenciados de consumo de alimento, indício da variada aceitação das dietas. Embora possa se sugerir que o uso de maior número de repetições experimentais pudesse reduzir o coeficiente de variação e indicar algum efeito da adição de FMB sobre o consumo de nutrientes fica patente que os ovinos

Tabela 2 - Médias, equações de regressão e coeficientes de variação (CV) dos consumos de nutrientes de ovinos alimentados com dietas contendo níveis crescentes de farelo do mesocarpo de babaçu (FMB) em substituição à silagem de capim elefante

\begin{tabular}{|c|c|c|c|c|c|c|c|}
\hline \multirow{2}{*}{ Variáveis } & \multicolumn{5}{|c|}{ Níveis de substituição (\%) } & \multirow{2}{*}{ Equações } & \multirow{2}{*}{$\mathrm{CV}(\%)$} \\
\hline & 0 & 21 & 38 & 62 & 78 & & \\
\hline \multicolumn{8}{|c|}{ Consumo de matéria seca } \\
\hline $\mathrm{g} \mathrm{dia}^{-1}$ & 477,7 & 626,2 & 734,7 & 799,9 & 715,9 & $\hat{\mathrm{Y}}=670,8^{\mathrm{ns}}$ & 38,7 \\
\hline$\% \mathrm{PV}$ & 1,6 & 1,9 & 2,6 & 2,6 & 2,2 & $\hat{\mathrm{Y}}=2,2^{\mathrm{ns}}$ & 37,7 \\
\hline $\mathrm{g} \mathrm{UTM}^{-1}$ & 38,1 & 46,0 & 59,9 & 60,8 & 51,9 & $\hat{\mathrm{Y}}=51,3^{\mathrm{ns}}$ & 37,6 \\
\hline \multicolumn{8}{|c|}{ Consumo de matéria orgânica } \\
\hline $\mathrm{g} \mathrm{dia}^{-1}$ & 456,6 & 599,6 & 704,7 & 767,2 & 688,0 & $\hat{\mathrm{Y}}=643,2^{\mathrm{ns}}$ & 38,7 \\
\hline$\% \mathrm{PV}$ & 1,6 & 1,8 & 2,5 & 2,5 & 2,1 & $\hat{\mathrm{Y}}=2,1^{\mathrm{ns}}$ & 37,7 \\
\hline $\mathrm{g} \mathrm{UTM}^{-1}$ & 36,4 & 44,0 & 57,5 & 58,3 & 49,9 & $\hat{\mathrm{Y}}=49,2^{\mathrm{ns}}$ & 37,5 \\
\hline \multicolumn{8}{|c|}{ Consumo de proteína bruta } \\
\hline $\mathrm{g} \mathrm{dia}^{-1}$ & 32,2 & 42,6 & 50,9 & 57,6 & 54,5 & $\hat{\mathrm{Y}}=47,6^{\mathrm{ns}}$ & 38,5 \\
\hline$\% \mathrm{PV}$ & 0,1 & 0,1 & 0,2 & 0,2 & 0,2 & $\hat{\mathrm{Y}}=0,2^{\mathrm{ns}}$ & 36,5 \\
\hline $\mathrm{g} \mathrm{UTM}^{-1}$ & 2,6 & 3,1 & 4,2 & 4,4 & 3,9 & $\hat{\mathrm{Y}}=3,6^{\mathrm{ns}}$ & 36,6 \\
\hline \multicolumn{8}{|c|}{ Consumo de fibra em detergente neutro } \\
\hline $\mathrm{g} \mathrm{dia}^{-1}$ & 368,7 & 446,5 & 482,4 & 474,3 & 383,9 & $\hat{\mathrm{Y}}=431,1^{\text {ns }}$ & 34,7 \\
\hline$\% \mathrm{PV}$ & 1,3 & 1,4 & 1,7 & 1,5 & 1,2 & $\hat{\mathrm{Y}}=1,4^{\mathrm{ns}}$ & 33,8 \\
\hline $\mathrm{g} \mathrm{UTM}^{-1}$ & 29,4 & 32,8 & 39,3 & 36,1 & 27,8 & $\hat{Y}=33,1^{\text {ns }}$ & 33,6 \\
\hline \multicolumn{8}{|c|}{ Consumo de fibra em detergente ácido } \\
\hline $\mathrm{g} \mathrm{dia}^{-1}$ & 226,8 & 281,6 & 313,1 & 315,9 & 264,1 & $\hat{\mathrm{Y}}=280,3^{\text {ns }}$ & 36,0 \\
\hline$\% \mathrm{PV}$ & 0,8 & 0,9 & 1,1 & 1,0 & 0,8 & $\hat{\mathrm{Y}}=0,9^{\mathrm{ns}}$ & 35,1 \\
\hline $\mathrm{g} \mathrm{UTM}^{-1}$ & 18,1 & 20,7 & 25,5 & 24,0 & 19,1 & $\hat{\mathrm{Y}}=21,5^{\mathrm{ns}}$ & 34,9 \\
\hline \multicolumn{8}{|c|}{ Consumo de hemicelulose } \\
\hline $\mathrm{g} \mathrm{dia}^{-1}$ & 141,9 & 164,7 & 168,9 & 157,9 & 119,0 & $\hat{\mathrm{Y}}=150,5^{\mathrm{ns}}$ & 32,6 \\
\hline$\% \mathrm{PV}$ & 0,5 & 0,5 & 0,6 & 0,5 & 0,4 & $\hat{\mathrm{Y}}=0,5^{\mathrm{ns}}$ & 31,6 \\
\hline $\mathrm{g} \mathrm{UTM}^{-1}$ & 11,3 & 12,1 & 13,8 & 12,0 & 8,6 & $\hat{\mathrm{Y}}=30,9^{\mathrm{ns}}$ & 31,3 \\
\hline
\end{tabular}

${ }^{n s}=\mathrm{P}>0,05$ 
apresentam elevada variação quanto à aceitação deste subproduto.

Moreno et al. (2010) observaram maiores CMS, com média de 802 gramas dia $^{-1}$ e $3,3 \%$ do PV para ovinos não castrados alimentados com dietas contendo cana de açúcar ou silagem de milho em dois níveis de concentrado. Já Ferreira et al. (2010) observaram CMS inferiores aos deste trabalho, 481,58 $\mathrm{g} \mathrm{dia}^{-1}$ e 44,82 $\mathrm{g} \mathrm{UTM}^{-1}$ para ovinos não castrados com peso médio corporal de $28,0 \mathrm{~kg}$ alimentados com silagem de capim elefante contendo subproduto de acerola. Guimarães (2010) verificou comportamento quadrático para os consumos em \% PV e em g UTM ${ }^{-1}$, com CMS máximo de 3,84\% PV, quando o FMB foi adicionado em $13 \%$ à silagem de mombaça (matéria natural), correspondendo à adição de 50,1\% na MS. Mudanças nos CMS de dietas contendo subprodutos são recorrentes na literatura conforme observado por Rêgo et al. (2010), que avaliaram silagem contendo subproduto desidratado de manga e Oliveira et al. (2010) que testaram casca de café, farelo de cacau e farelo de mandioca. Desta forma, é fundamental salientar que o FMB apresenta algumas características que podem justificar a ausência de respostas consistentes com relação ao consumo de nutrientes. As principais características são sua baixa densidade, elevada pulverulência e granulometria fina. Normalmente, essas características isoladas ou em conjunto tendem a limitar as condições ruminais, variando individualmente entre os animais.

Os ovinos avaliados neste experimento eram mais uniformes do que os utilizados por Rêgo et al. (2010), que observaram alterações no consumo de nutrientes com a adição de subprodutos agroindustriais. Destacase que o consumo médio de nutrientes observado no presente estudo, não supriu os requerimentos de mantença, conforme indica o balanço de nitrogênio (BN) negativo para as dietas, com exceção do nível de $38 \%$ de adição de FMB (Tabela 5). A quantidade de nitrogênio da dieta limita a digestão da fração fibrosa, por não permitir o desenvolvimento adequado dos microorganismos ruminais, e, portanto limita o consumo de MS, sendo, segundo Van Soest (1994), necessário no mínimo $1 \%$ de nitrogênio na dieta ou $6,25 \%$ de PB. Esses níveis foram atingidos apenas a partir de $38 \%$ de inclusão de FMB. A adição de uréia ao FMB utilizado nas dietas foi uma tentativa de ajustar o teor de PB para o consumo do mínimo recomendado, no entanto, a silagem de capim elefante utilizada apresentou níveis abaixo do esperado, e desta forma, o acréscimo de FMB promoveu aumento da PB nas dietas (Tabela 1). A baixa quantidade de nitrogênio das dietas pode ter sido um fator importante na determinação do CMS dos animais, os quais foram inferiores ao recomendado pelo National Research Council (2007).
Esperava-se que a redução dos conteúdos de FDN, FDA e HEM das dietas com a inclusão de FMB (Tabela 1), em semelhança dos CMS, reduzisse os consumos destes nutrientes, porém, este comportamento não foi observado, e os consumos medidos tanto em $\mathrm{g} \mathrm{dia}{ }^{-1}$, como em $\%$ PV e g $\mathrm{UTM}^{-1}$ não foram alterados (Tabela 2). Devido à capacidade de seleção dos alimentos pelos ovinos, observou-se que os animais preferiram consumir mais silagem, uma vez que as sobras recolhidas no cocho correspondiam essencialmente a FMB. Este comportamento seletivo pode ter ocorrido com o objetivo de aumentar o consumo de fibra longa, já que o FMB apresenta granulometria fina, com 96\% das partículas inferiores a 1,18 mm. Desta forma, mesmo com o FMB tendo diminuído o teor de FDN das dietas, a seleção permitiu que os animais continuassem a consumir quantidades semelhantes deste nutriente. Adicionalmente, pode existir alguma característica que prejudique a palatabilidade do FMB.

O consumo de CNF (CCNF) em $\mathrm{g}$ dia $^{-1}$ teve comportamento quadrático (Tabela 3), enquanto o CCNF em \% PV aumentou em 0,008\% para cada ponto percentual de FMB na dieta, e o consumo em $\mathrm{g} \mathrm{UTM}^{-1}$ aumentou em 0,19 gramas para cada ponto percentual de FMB na dieta. Esse resultado foi obtido em função do aumento de CNF nas dietas à medida que se adicionou FMB às dietas. A maior quantidade de CNF nas dietas com FMB é consequência do maior teor deste nutriente no subproduto, 4,7 vezes mais que o encontrado na silagem de capim elefante. $\mathrm{O}$ amido é o principal polissacarídeo armazenado em grãos, colmos e folhas de leguminosas e gramíneas, sendo o principal componente da fração de CNF do FMB, 52\% da MS total (PAVLAK et al., 2007), tornando as dietas com FMB mais ricas em amido. Já o consumo de CHOT não foi influenciado pelas dietas experimentais, já que a silagem e o FMB apresentaram conteúdos semelhantes deste nutriente e o consumo de MS não foi alterado.

Para o consumo de EE (CEE) não houve diferença significativa em g dia ${ }^{-1}$. Entretanto, em \% PV e em g UTM ${ }^{-1}$, observaram-se decréscimo com o aumento de FMB nas dietas (Tabela 3). Como a silagem de capim elefante apresentava teor de EE três vezes superior ao teor do FMB (1,9 e 0,7\% de EE, respectivamente), já era esperado que as dietas com maior nível de FMB proporcionassem menores CEE, como foi verificado quando os valores foram expressos em \%PV e g UTM ${ }^{-1}$. Embora os animais possam ter exercido seleção da dieta, buscando maior ingestão de silagem, esta não foi suficiente para inverter essa tendência.

Não foi detectada diferença estatística entre os tratamentos quando avaliados o consumo de NDT (CNDT) em g dia ${ }^{-1}$ (Tabela 3 ), havendo comportamento quadrático nos consumos em \% PV e em g UTM ${ }^{-1}$. Segundo a equação de regressão, máximos consumos de 
NDT em \% PV e g UTM ${ }^{-1}$ são obtidos em 37,3 e 37,9\% de FMB na dieta respectivamente. Este resultado demonstra que apesar do ponto de maior digestibilidade da MS ter ocorrido com $10 \%$ de substituição, e do teor de NDT nas dietas ter reduzido linearmente (Tabela 4), a inclusão deste subproduto na dieta permitiu aos animais consumirem maiores quantidades de energia. Os CNDT máximos foram observados com níveis de inclusão, próximos

Tabela 3 - Médias, equações de regressão e coeficientes de variação (CV) dos consumos de nutrientes de ovinos alimentados com dietas contendo níveis crescentes de farelo do mesocarpo de babaçu (FMB) em substituição à silagem de capim elefante

\begin{tabular}{|c|c|c|c|c|c|c|c|c|}
\hline \multirow{2}{*}{ Variáveis } & \multicolumn{5}{|c|}{ Níveis de substituição (\%) } & \multirow{2}{*}{ Equações } & \multirow{2}{*}{$\mathrm{R}^{2}$} & \multirow{2}{*}{$\mathrm{CV}(\%)$} \\
\hline & 0 & 21 & 38 & 62 & 78 & & & \\
\hline \multicolumn{9}{|c|}{ Consumo carboidratos não fibrosos } \\
\hline $\mathrm{g} \mathrm{dia}^{-1}$ & 45,1 & 99,2 & 160,8 & 225,3 & 243,4 & $1 / \hat{\mathrm{Y}}=0,02-0,0006 \mathrm{FMB}+0,000005 \mathrm{FMB}^{2 * *}$ & 83,0 & 45,7 \\
\hline$\% \mathrm{PV}$ & 0,2 & 0,3 & 0,6 & 0,7 & 0,7 & $\hat{\mathrm{Y}}=0,18+0,008 \mathrm{FMB}^{*} *$ & 45,8 & 51,5 \\
\hline $\mathrm{g} \mathrm{UTM}^{-1}$ & 3,6 & 7,3 & 13,1 & 17,1 & 17,7 & $\hat{\mathrm{Y}}=4,16+0,19 \mathrm{FMB}^{* *}$ & 46,5 & 51,6 \\
\hline \multicolumn{9}{|c|}{ Consumo de carboidratos totais } \\
\hline $\mathrm{g} \mathrm{dia}^{-1}$ & 413,8 & 545,7 & 643,2 & 699,6 & 627,3 & $\hat{\mathrm{Y}}=585,9^{\mathrm{ns}}$ & - & 38,9 \\
\hline$\% \mathrm{PV}$ & 1,4 & 1,7 & 2,3 & 2,3 & 1,9 & $\hat{Y}=1,9^{\text {ns }}$ & - & 37,9 \\
\hline $\mathrm{g} \mathrm{UTM}^{-1}$ & 33,0 & 40,1 & 52,5 & 53,2 & 45,5 & $\hat{\mathrm{Y}}=44,8^{\mathrm{ns}}$ & - & 37,7 \\
\hline \multicolumn{9}{|c|}{ Consumo de extrato etéreo } \\
\hline $\mathrm{g} \mathrm{dia}^{-1}$ & 10,6 & 11,3 & 10,5 & 9,9 & 6,2 & $\hat{\mathrm{Y}}=9,7^{\mathrm{ns}}$ & - & 32,1 \\
\hline$\% \mathrm{PV}$ & 0,04 & 0,04 & 0,04 & 0,03 & 0,02 & $\hat{\mathrm{Y}}=0,04-0,0002 \mathrm{FMB}^{*}$ & 24,0 & 31,4 \\
\hline $\mathrm{g} \mathrm{UTM}^{-1}$ & 0,8 & 0,8 & 0,9 & 0,8 & 0,4 & $\hat{\mathrm{Y}}=0,92-0,0044 \mathrm{FMB}^{*}$ & 24,0 & 30,8 \\
\hline \multicolumn{9}{|c|}{ Consumo de nutrientes digestíveis totais } \\
\hline $\mathrm{g} \mathrm{dia}^{-1}$ & 272,8 & 350,0 & 379,7 & 350,8 & 257,5 & $\hat{\mathrm{Y}}=322,17^{\mathrm{ns}}$ & - & 37,2 \\
\hline$\% \mathrm{PV}$ & 0,9 & 1,1 & 1,4 & 1,1 & 0,8 & $\hat{\mathrm{Y}}=0,89+0,0194 \mathrm{FMB}-0,0003 \mathrm{FMB}^{2 *}$ & 23,4 & 32,9 \\
\hline $\mathrm{g} \mathrm{UTM}^{-1}$ & 21,8 & 25,7 & 30,9 & 26,6 & 18,8 & $\hat{\mathrm{Y}}=21,05+0,45 \mathrm{FMB}-0,006 \mathrm{FMB}^{2 *}$ & 22,3 & 32,8 \\
\hline
\end{tabular}

$* *=\mathrm{P}<0,01 ; *=\mathrm{P}<0,05 ;{ }^{\text {ns }}=\mathrm{P}>0,05$

Tabela 4 - Médias, equações de regressão, e análise de variância das digestibilidades aparentes dos nutrientes de dietas contendo farelo do mesocarpo de babaçu em substituição à silagem de capim elefante

\begin{tabular}{|c|c|c|c|c|c|c|c|c|}
\hline \multirow{2}{*}{ Variáveis $(\%)$} & \multicolumn{5}{|c|}{ Níveis de substituição (\%) } & \multirow{2}{*}{ Equações } & \multirow{2}{*}{$\mathrm{R}^{2}$} & \multirow{2}{*}{$\mathrm{CV}(\%)$} \\
\hline & 0 & 21 & 38 & 62 & 78 & & & \\
\hline $\mathrm{DAMS}^{1}$ & 51,3 & 52,3 & 48,2 & 39,2 & 31,8 & $\hat{\mathrm{Y}}=51,74+0,08 \mathrm{FMB}-0,004 \mathrm{FMB}^{2 *} *$ & 72,0 & 11,1 \\
\hline $\mathrm{DAMO}^{2}$ & 59,0 & 57,1 & 53,0 & 45,0 & 37,8 & $\hat{\mathrm{Y}}=61,39-0,28 \mathrm{FMB}^{* *}$ & 80,0 & 7,05 \\
\hline DAFDN $^{3}$ & 61,0 & 53,3 & 44,4 & 27,1 & 10,2 & $\hat{\mathrm{Y}}=64,98-0,65 \mathrm{FMB}^{* *}$ & 92,0 & 11,1 \\
\hline DAFDA $^{4}$ & 59,5 & 50,2 & 40,7 & 21,8 & 4,7 & $\hat{\mathrm{Y}}+3=66,23-0,70 \mathrm{FMB}^{*} *$ & 92,0 & 0,94 \\
\hline DAHEM $^{5}$ & 83,8 & 85,8 & 86,3 & 85,9 & 77,0 & $\hat{\mathrm{Y}}=83,77^{\mathrm{ns}}$ & 24,0 & 8,4 \\
\hline $\mathrm{DAPB}^{6}$ & 46,5 & 44,9 & 42,5 & 40,4 & 37,5 & $\hat{\mathrm{Y}}=46,85-0,11 \mathrm{FMB} *$ & 24,0 & 12,6 \\
\hline $\mathrm{DAEE}^{7}$ & 36,5 & 38,6 & 38,3 & 24,9 & $-58,7$ & $(\hat{\mathrm{Y}}+200)^{2}=54154,0+519,31 \mathrm{FMB}-10,71 \mathrm{FMB}^{2 * *}$ & 37,0 & 28,2 \\
\hline $\mathrm{DACT}^{8}$ & 60,5 & 58,4 & 54,1 & 45,7 & 38,5 & $\hat{\mathrm{Y}}=62,92-0,29 \mathrm{FMB} * *$ & 84,0 & 6,9 \\
\hline $\mathrm{DACNF}^{9}$ & 57,3 & 81,4 & 83,1 & 85,2 & 84,1 & $\hat{\mathrm{Y}}=59,02+1,05 \mathrm{FMB}-0,009 \mathrm{FMB}^{2 * *}$ & 46,0 & 13,6 \\
\hline $\mathrm{NDT}^{10}$ & 57,4 & 55,5 & 51,6 & 43,6 & 35,9 & $\hat{\mathrm{Y}}=50,91-0,28 \mathrm{FMB}^{*} *$ & 81,0 & 6,9 \\
\hline
\end{tabular}

$*^{*}=\mathrm{P}<0,01 ; *=\mathrm{P}<0,05 ;{ }^{\mathrm{ns}}=\mathrm{P}>0,05 .{ }^{1} \mathrm{DAMS}$ - digestibilidade aparente da matéria seca; ${ }^{2} \mathrm{DAMO}$ - digestibilidade aparente da matéria orgânica; ${ }^{3} \mathrm{DAFDN}$ - digestibilidade aparente da fibra em detergente neutro; ${ }^{4}$ DAFDA - digestibilidade aparente da fibra em detergente ácido; ${ }^{5}$ DAHEM - digestibilidade aparente da hemicelulose; ${ }^{6} \mathrm{DAPB}$ - digestibilidade aparente da proteína bruta; ${ }^{7} \mathrm{DAEE}$ - Digestibilidade aparente do extrato etéreo; ${ }^{8} \mathrm{DACT}$ - digestibilidade aparente dos carboidratos totais; ${ }^{9} \mathrm{DACNF}$ - digestibilidade aparente dos carboidratos não fibrosos; ${ }^{10} \mathrm{NDT}$ - nutrientes digestíveis totais 
a $40 \%$ e são decorrentes do aumento numérico do CMS. Embora a diferença não tenha sido detectada estatisticamente para esta variável, a análise foi sensível à diferença quando os dados foram apresentados como CNDT. O aumento no CNDT indica a viabilidade biológica do FMB como alimento suplementar em dietas que apresentam como base volumosos de baixa qualidade, o que pode proporcionar manutenção do nível produtivo ou melhoria no desempenho.

A digestibilidade aparente da MS (DAMS) apresentou comportamento quadrático e a substituição de $10,0 \%$ da silagem de capim elefante pelo FMB proporcionou digestibilidade máxima de $52,5 \%$ (Tabela 4). Em contrapartida, a digestibilidade aparente da MO (DAMO) decresceu 0,28\% para cada ponto percentual de FMB na dieta, verificando-se que a dieta com substituição de $78 \%$ silagem por FMB teve DAMS observada de $51,6 \%$, e DAMO de $56,2 \%$, menores do que a dieta padrão. Da mesma forma, a digestibilidade aparente da FDN (DAFDN), reduziu 0,65 ponto percentual por percentual de acréscimo de FMB e a digestibilidade aparente da FDA (DAFDA) teve decréscimo de 0,7 ponto percentual para cada ponto percentual de substituição da silagem por FMB, contudo não houve influência na digestibilidade aparente da HEM (DAHEM).

Com o incremento do FMB nas dietas era esperado que houvesse correlação negativa entre a DAMS e o CFDN, no entanto, este resultado não foi observado $(\mathrm{r}=0,18 ; \mathrm{P}=0,43)$. Segundo o National Reserach Council (1987), a digestibilidade dos alimentos consumidos pelos ruminantes está relacionada à cinética da digestão e sua passagem pelo rúmen, apresentando estreita associação com a digestão da fibra já que esta delimita a taxa de desaparecimento do material no trato digestório. Neste modelo, o tempo de retenção no aparelho digestivo é influenciado, entre outros fatores, pelas características físicas da dieta e tempo de ruminação, em que o consumo de matéria seca digestível é afetado mais pela fibra digestível e taxa de passagem que pela taxa de digestão de fibra. Pelas características físicas do FMB, que apresenta granulometria fina, se pressupõe aumento da taxa de passagem do alimento pelo trato gastrointestinal, o que reduz o tempo de ação dos microorganismos ruminais sobre as partículas de alimento, refletindo na redução da digestibilidade das frações FDN e FDA, e consequentemente da MS.

Guimarães (2010) observaram que o aumento do nível de FMB na silagem de mombaça reduziu a digestibilidade da FDN e da MS, atribuindo este comportamento ao alto teor de lignina do subproduto $(13,2 \%)$. Neste trabalho, a substituição da silagem por FMB elevou os teores de lignina das dietas, todavia, não foi suficiente para interferir na DAFDN. A DAMS sofre influência da digestibilidade dos nutrientes, portanto, correlacionou-se positivamente com a digestibilidade da FDN e da FDA, ambas $\mathrm{r}=0,88(\mathrm{P}<0,001)$, dos CHOT, $\mathrm{r}=0,94(\mathrm{P}<0,001)$; da $\mathrm{PB}, \mathrm{r}=0,76(\mathrm{P}<0,001)$ e do $\mathrm{EE}, \mathrm{r}=0,52(\mathrm{P}=0,018)$, porém, não houve correlação significativa com a DACNF, $\mathrm{r}=-0,12(\mathrm{P}=0,59)$.

A digestibilidade da PB (DAPB) reduziu em $0,11 \%$ para cada ponto percentual de substituição da silagem de capim elefante pelo FMB, embora tenha havido elevação do teor de PB. Contudo, observou-se que com o aumento de FMB nas dietas, os conteúdos de NIDN e de NIDA foram reduzidos (Tabela 1). Isto ocorreu porque grande parte do $\mathrm{N}$ contido no FMB foi oriundo da adição de uréia, apresentando maiores teores de proteína degradável no rúmen (PDR). Diante do exposto, era esperado que houvesse melhoria da condição ruminal para degradação dos nutrientes, visto que a maior disponibilidade de $\mathrm{N}$ propicia o crescimento da microbiota ruminal. No entanto, não foi observada diferença no CPB ou correlação entre a DAMS e o CPB ( $\mathrm{r}=-0,008 ; \mathrm{P}=0,97)$.

Rotger et al. (2006) estudaram o efeito da sincronização ruminalde carboidratos e proteínas, relatando que estes parecem exercer efeito sobre a fermentação in vitro. De acordo com Santos (2006), a sincronização da degradação da proteína com a de carboidratos no rúmen permite maximizar o uso da PDR e minimizar perdas de amônia. Ainda afirma que o nitrogênio não protéico (NNP) é degradado rapidamente (> 300\%/hora), mas nem sempre é degradado totalmente no rúmen em decorrência da taxa de passagem. Por sua vez o amido tem taxa de degradação de 10 a 40\%/hora. Desta forma, se pressupõe que mesmo havendo maior disponibilidade de PDR nas dietas com FMB e maior quantidade de CNF disponíveis, a conversão destes nutrientes em proteína microbiana não foi eficiente devido à falta de sincronia entre as taxas de degradação da uréia e amido. Além disso, as bactérias fermentadoras de CNF têm requerimento maior de aminoácidos e peptídeos, os quais são obtidos pelo animal com o consumo de proteína verdadeira, claramente deficiente em todas as dietas experimentais.

As DAFDN, DAFDA e DAHEM tiveram correlações negativas com o $\mathrm{CPB}$ com $\mathrm{r}=-0,45(\mathrm{P}=$ $0,045) ; \mathrm{r}=-0,43(\mathrm{P}=0,054)$ e $\mathrm{r}=-0,64(\mathrm{P}=0,002)$, respectivamente, demonstrando que o $\mathrm{CPB}$ influenciou negativamente a digestibilidade das frações fibrosas da dieta. Guimarães (2010) avaliando a DAMS de silagem contendo níveis de FMB verificaram decréscimo da DAMS e atribuíram aos baixos níveis de PB das dietas abaixo de 7\%. Figueira et al. (2010), observaram que o fornecimento de compostos nitrogenados (uréia e sulfato de amônia) até níveis próximos de 9\% melhoraram a 
digestibilidade da MS melhorando o aproveitamento de forragens de baixa qualidade.

A digestibilidade aparente do EE (DAEE) apresentou comportamento quadrático, atingindo digestibilidade negativa, como foi observado na dieta com $78 \%$ de FMB. Como a digestibilidade é calculada por diferença entre o consumido e o excretado proporcionalmente ao consumido, para que haja digestibilidade negativa, na excreção de EE deve estar computado tanto o EE da dieta não digerido, quanto o EE endógeno. Segundo Van Soest (1982), matérias microbianas e endógenas são perdidas nas fezes. A matéria microbiana excretada corresponde a paredes celulares indigeridas no rúmen, e células produzidas no trato, sendo esta composta por parede celular indigestível, carboidrato bacteriano, gordura e cinzas, interferindo no cômputo real da digestibilidade.

A digestibilidade aparente dos CHOT (DACHOT) reduziu com o aumento de FMB nas dietas (Tabela 4). Já a digestibilidade aparente dos CNF (DACNF) teve comportamento quadrático, com ponto de máxima em 58,3\% de FMB. O aumento da DACNF provavelmente deu-se em virtude do maior conteúdo de amido das dietas com FMB, enquanto a redução da DACNF, a partir de 58,3\% de FMB pode ter ocorrido em razão da maior taxa de passagem da digesta pelo rúmen. De maneira geral, os CNF são fermentados rapidamente no rúmen para a formação de ácidos graxos voláteis que reduzem o $\mathrm{pH}$ ruminal. Em dietas com predominância de alimentos volumosos, em virtude da baixa concentração de CNF ou carboidratos solúveis o pH ruminal permanece entre 6,2 e 7,0, enquanto dietas a base de concentrados o $\mathrm{pH}$ ruminal oscila entre 5,5 e 6,5. Em condições de pH abaixo de 6,0, a digestão da fibra é diminuída por inibição microbiana (NÚSSIO; CAMPOS; LIMA., 2006). Observou-se que tanto o CCNF quanto a DACNF correlacionaram-se negativamente com a digestibilidade das frações FDN $(r=-0,69 ; \mathrm{P}<0,001 \mathrm{e}$ $\mathrm{r}=-0,48 ; \mathrm{P}=0,03$, respectivamente $)$ e FDA $(\mathrm{r}=-0,67 ; \mathrm{P}=$ 0,001 , e $\mathrm{r}=-0,49 ; \mathrm{P}=0,02$, respectivamente). $\mathrm{O}$ aumento de CNF nas dietas aliado ao aumento na DACNF pode ter proporcionado queda no $\mathrm{pH}$ ruminal dos animais que receberam dietas com maiores níveis de FMB tornando o ambiente ruminal inadequado ao desenvolvimento das bactérias que degradam as frações fibrosas, justificando as correlações negativas e parte da redução na digestibilidade da FDN e FDA, refletindo negativamente na DAMS com correlação de $-0,45(\mathrm{P}=0,04)$ com o CCNF.

Em consequência da redução da digestibilidade de alguns dos nutrientes avaliados, o percentual de NDT da dieta decresceu com a substituição de silagem por FMB (Tabela 4 ), reduzindo em $0,28 \%$ para cada ponto percentual de FMB nas dietas. As médias estimadas foram 50,9; 45,3; 39,7; 34,1 e 28,5\% de NDT para as dietas padrão, com 21; 38; 62 e $78 \%$ de FMB, em que comparando com a dieta padrão houve queda na digestibilidade dos nutrientes de 12,$4 ; 28,2 ; 49,3$ e 78,6\%, respectivamente. O percentual de NDT foi negativamente correlacionado com o CCNF ( $\mathrm{r}=-0,59$; $\mathrm{P}=0,006)$, ou seja, com o aumento do CCNF esperase queda no percentual total de NDT, em função da influência negativa do CCNF na DAFDN. A correlação entre NDT e digestibilidade dos nutrientes DAPB ( $\mathrm{r}=$ $0,72 ; \mathrm{P}<0,001)$, DAFDN $(\mathrm{r}=0,96 ; \mathrm{P}<0,001)$ e DAEE $(\mathrm{r}=0,49 ; \mathrm{P}=0,02)$ foi de alta a média, uma vez que o NDT nada mais é que o somatório destes, com a ressalva de seus valores energéticos. A DACNF não apresentou correlação significativa $(\mathrm{r}=-0,30 ; \mathrm{P}=0,18)$ com o percentual de NDT.

Guimarães (2010) verificaram resposta quadrática para o percentual de NDT em que o ponto de máxima quantidade de NDT foi obtido com 18,9\% de adição de FMB na MS da silagem de capim mombaça, com 57,75\% de NDT. Naquele trabalho, parte da redução do NDT foi atribuída ao aumento do teor de lignina já que esta interfere na digestibilidade de vários nutrientes (FDN, FDA e PB). Este argumento também foi utilizado por Carvalho et al. (2007) trabalhando com farelo de cacau para a redução da digestibilidade da matéria seca in vitro. No presente estudo a magnitude da diferença nos teores de lignina não

Tabela 5 - Médias, equações de regressão e coeficientes de variação (CV) do balanço de nitrogênio, em gramas dia ${ }^{-1}$, em ovinos alimentados com dietas contendo farelo de mesocarpo de babaçu (FMB) em substituição a silagem de capim elefante

\begin{tabular}{lccccccc}
\hline \multirow{2}{*}{ Variáveis } & \multicolumn{9}{c}{ Níveis de substituição (\%) } & \multirow{2}{*}{ Equações } & CV $(\%)$ \\
\cline { 2 - 5 } & 0 & 21 & 38 & 62 & 78 & & - \\
N ingerido & 5,18 & 6,84 & 8,17 & 9,24 & 8,73 & - & - \\
N fecal & 2,77 & 3,73 & 4,60 & 5,45 & 5,43 & - & - \\
N urina & 2,44 & 3,70 & 3,15 & 4,50 & 5,68 & - & - \\
Balanço de N & $-0,03$ & $-0,59$ & 0,42 & $-0,71$ & $-2,38$ & $\hat{\mathrm{Y}}=-0,66^{\mathrm{ns}}$ & 41,22 \\
\hline
\end{tabular}

ns - não significativo 
suporta as alterações observadas nas digestibilidades das frações fibrosas.

O BN não foi influenciado pelas dietas experimentais (Tabela 5), porém, com exceção da dieta contendo $38 \%$ de inclusão de FMB todas as demais apresentaram $\mathrm{BN}$ negativo. Esse resultado já era esperado uma vez que os teores de PB das dietas foram abaixo das exigências de mantença para essa categoria de ovinos (NATIONAL RESEARCH COUNCIL, 2007). Além disso, a falta de sincronia no uso entre carboidratos e NNP e a taxa de passagem da digesta pelo rúmen também podem ter promovido o escape de $\mathrm{N}$.

É recomendado o estudo da cinética e dinâmica ruminais de dietas contendo FMB, que poderão esclarecer o comportamento de parâmetros nutricionais importantes. Assim, como o conhecimento do comportamento ingestivo dos animais pode elucidar problemas relacionados ao consumo (CARVALHO et al., 2004) e possibilitar ajustes de manejo alimentar para obtenção de melhores desempenhos (BARROSOI et al. 2007; CARDOSO et al., 2006).

\section{CONCLUSÃO}

O uso do farelo do mesocarpo de babaçu em substituição à silagem de capim elefante em dietas para ovinos aumenta os consumos de carboidratos não fibrosos e dos nutrientes digestíveis totais. Este subproduto, embora reduza a digestibilidade das frações fibrosas da dieta, pode ser aproveitado como fonte energética para ruminantes.

\section{REFERÊNCIAS}

BARROSOI, D. D. et al. Desempenho bioeconômico de ovinos terminados em confinamento alimentados com subproduto desidratado de vitivinícolas associado a diferentes fontes energéticas. Revista Ciência Agronômica, v. 38, n. 02, p. 192-198, 2007.

BOLZAN, I. T. et al. Consumo e digestibilidade em ovinos alimentados com dietas contendo grão de milho moído, inteiro ou tratado com uréia, com três níveis de concentrado. Ciência Rural, v. 37, n. 01, p. 229-234, 2007.

CARDOSO, A. R. et al. Comportamento ingestivo de cordeiros alimentados com dietas contendo diferentes níveis de fibra em detergente neutro. Ciência Rural, v. 36, n. 02, p. 604-609, 2006.

CARVAlHO, G. G. P. et al. Comportamento ingestivo de cabras leiteiras alimentadas com farelo de cacau ou torta de dendê. Pesquisa Agropecuária Brasileira, v. 39, n. 09, p. 919-925, 2004
CARVALHO, G. G. P. et al. Valor nutritivo de silagens de capim elefante emurchecido ou com adição de farelo de cacau. Revista Brasileira de Zootecnia, n. 36, n. 05, p. 1495-1501, 2007. Suplemento.

FERREIRA, A. C. H. et al. Consumo e digestibilidade de silagens de capim-elefante com diferentes níveis de subproduto da agroindústria da acerola. Revista Ciência Agronômica, v. 41, n. 04, p. 693-701, 2010.

FIGUEIRA, J. F. et al. Intake and digestibility in cattle under grazing supplemented with nitrogenous compounds during dry season. Revista Brasileira de Zootecnia, v. 39, n. 06, p. 1303-1312, 2010.

FORBES, J. M. Natural feeding behavior and feed section. In: HEIDDE, D. et al. (Ed.). Regulation of feed intake. CAB International, 1999. p. 03-12.

GUIMARÃES, C. R. R. Valor nutritivo da silagem de capim mombaça (Panicum maximum) com níveis crescentes de adição do farelo do mesocarpo do babaçu (Orbignya sp). 2010. 81 f. Dissertação (Mestrado em Ciência Animal Tropical) - Universidade Federal do Tocantins, Araguaína, 2010.

MIOTTO, F. R. C. et al. Desempenho produtivo de tourinhos Nelore $\mathrm{x}$ Limousin alimentados com dietas contendo gérmen de milho integral. Revista Ciência Agronômica, v. 40, n. 04, p. 624-632, 2009.

MORENO, G. M. B. et al. Desempenho, digestibilidade e balanço de nitrogênio em cordeiros alimentados com silagem de milho ou cana-de-açúcar e dois níveis de concentrado. Revista Brasileira de Zootecnia, v. 39, n. 04, p. 853-860, 2010.

NATIONAL RESEARCH COUNCIL. Predicting feed intake of food-producing animals. Washington, D.C.: National Academic of Sciences, 1987. $85 \mathrm{p}$.

NATIONALRESEARCHCOUNCIL. Nutrient requirements of sheep. 6. ed. Washington, D.C.: National Academy Press, 2007. 362 p.

NEIVA, J. N. M. et al. Farelo de glúten de milho em dietas para ovinos em confinamento. Revista Ciência Agronômica, v. 36, n. 01, p. 111-117, 2005.

NÚSSIO, L. G.; CAMPOS, F. T.; LIMA, M. L. M. Metabolismo de carboidratos estruturais. In: BERCHIELLI, T. T.; PIRES, A. V.; OLIVEIRA, S. G. (Ed.). Nutrição de ruminantes. Jaboticabal: FUNEP, 2006. cap. 7, p. 183-228.

OLIVEIRA, J. B. et al. Subprodutos industriais na ensilagem de capim-elefante para cabras leiteiras: consumo, digestibilidade de nutrientes e produção de leite. Revista Brasileira de Zootecnia, v. 39, n. 02, p. 411-418, 2010.

PACHECO, P. S. et al. Avaliação econômica da terminação em confinamento de novilhos jovens e superjovens de diferentes grupos genéticos. Revista Brasileira de Zootecnia, v. 36, n. 01, p. 309-320, 2006.

PAVLAK, M. C. M. et al. Aproveitamento da farinha do mesocarpo do babaçu (Orbignya martiana) para obtenção de etanol. Evidência, v. 07, n. 01, p. 7-24, 2007. 
RÊGO, M. M. T. et al. Intake, nutrients digestibility and nitrogen balance of elephant grass silages with mango by-product addition. Revista Brasileira de Zootecnia, v. 39, n. 01, p. 74-80, 2010.

ROTGER, A. et al. Effects of nonstructural carbohydrates and protein sources on intake, apparent total tract digestibility, and ruminal metabolism in vivo and in vitro with highconcentrate beef cattle diets. Journal of Animal Science, v. 84, n. 05, p. 1188-1196, 2006.

SANTOS, F. A. P. Metabolismo de proteínas. In: BERCHIELLI, T. T.; PIRES, A. V.; OLIVEIRA, S.G. (Ed.). Nutrição de ruminantes. Jaboticabal: FUNEP, 2006. cap. 9, p. 255-286.

SILVA, D. J.; QUEIROZ, A. C. Análise de alimentos: métodos químicos e biológicos. 3. ed. Viçosa, MG: Editora UFV, 2002. 235 p.

SILVA, J. F. C; LEÃO, M. I. Fundamentos da Nutrição dos Ruminantes. Piracicaba, SP: Livroceres, 1979. 384 p.
SILVA, N. R. Desempenho produtivo de bovinos de corte alimentados com dietas contendo diferentes níveis de farelo do mesocarpo do babaçu. 2008. 75 f. Dissertação (Mestrado em Ciência Animal Tropical) - Universidade Federal do Tocantins, Araguaína, 2008.

SNIFFEN, C. J. et al. A net carbohydrate and protein system for evaluating cattle diets: II. Carbohydrate and protein availability. Journal of Animal Science, v. 70, n. 11, p. 3562-3577, 1992.

VAN SOEST, P. J. Nutritional Ecology of the Ruminant. Cornell University. 1982. 374 p.

VAN SOEST, P. J. Nutritional ecology of the ruminant. 2. ed. Cornell University, 1994. , 476 p.

ZAMBOM, M. A. et al. Desempenho e digestibilidade dos nutrientes de rações com casca do grão de soja em substituição ao milho para cabras Saanen em lactação e no pré-parto. Revista Brasileira de Zootecnia, v. 37, n. 07, p. 1311-1318, 2008. 